Original Research Paper

\title{
Blockade of Group I Metabotropic Glutamate Receptors (mGluRs) Activation Inhibits Nociception Following Descending Colon Distension in Sheep
}

\author{
${ }^{1}$ Bogdan F. Kania, ${ }^{2}$ Danuta Wrońska and ${ }^{3}$ Mikolaj A. Gralak \\ ${ }^{I}$ Department of Biotechnology, University Veterinary Medicine JU-AU Centre, \\ Hugon Kollataj Agricultural University in Cracow, Poland \\ ${ }^{2}$ Department of Animal Physiology and Endocrinology, Faculty of Animal Sciences, \\ Hugon Kollataj University of Agriculture in Cracow, Poland \\ ${ }^{3}$ Department of Physiological Sciences, Faculty of Veterinary Medicine, \\ Warsaw University of Life Sciences-SGGW, Warsaw, Poland
}

Article history

Received: 4-07-2014

Revised: 20-10-2014

Accepted: 05-12-2014

Corresponding Author:

Bogdan F. Kania

Department of Biotechnology,

University Veterinary Medicine

JU-AU Centre, Hugon Kollataj

Agricultural University in

Cracow, 24/28 Al.

Mickiewicza St., 30-059

Cracow, Poland

Email: b.kania@ur.krakow.pl

\begin{abstract}
Expression of mGluRs of groups I and II was found in structures of CNS closely related with nociception: Spinal cord superficial fields, responsible for pain filling or modulation of neurotransmission in the peripheral receptors. The present study examined contribution of mGluRs to the development and maintenance of changes in behavioral and clinical symptoms caused by visceral pain. Experiments were carried out in fourth stages (each of six Polish Merino ewes). Every experiment was performed simultaneously on two fasted animals, which were placed in two individual cages at one-week intervals. Sheep were fitted with a permanent stainless steel cannula in the lateral ventricle of the brain. Blood was collected before and few times after intracerebroventricular (i.c.v.) administration of the mGluR $_{1}$ antagonist: L-2-Amino-3-phosphonopropionic acid (L-AP3). The L-AP3 was infused at doses: $0.2,0.4$ or $0.8 \mathrm{mg} /$ animal, $10 \mathrm{~min}$ before the provoking of visceral pain by distention of Descending Colon (CD) with the rubber balloon of $200 \mathrm{~mL}$ water. This data demonstrated that the development and maintenance of the visceral pain symptoms of the $\mathrm{CD}$ is dependent on activation of $\mathrm{mGluR}_{1}$ in the CNS and that these receptors play a crucial role in modulating experimental acute visceral pain. The group I of the mGluR antagonist prevent behavioral, clinical and neuroendocrine symptoms of visceral pain. They can be possibly used in cases of acute visceral pain, especially, in combination with opioid agonists. Their simultaneous administration would probably allow minimizing dose of opioids. This knowledge can be also useful in palliative medicine.
\end{abstract}

Keywords: L-2-Amino-3-Phosphonopropionic Acid (L-AP3), Visceral Pain, Cortisol, Catecholamines, Sheep

\section{Introduction}

Glutaminergic receptors have complicated molecular structures comprehensive to excitatory amino acids (glutamate, aspartate and glycine). They include two families: Ionotropic (NMDA) divided into three classes (NMDA, AMPA and kainate) and Metabotropic Glutamate Receptors (mGluRs). Eight subtypes of mGluRs have been already identified. They have been classified into three groups based on the amino acid sequence similarity and of transduction mechanisms (Pin and Duvoisin, 1995). Group I of the mGluRs includes subclasses mGluR $_{1 \mathrm{~A}, 1 \mathrm{~B}, 1 \mathrm{C}}$ and mGluR $_{5 \mathrm{~A}, 5 \mathrm{~B}}$, which activate phospholipases and induce synthesis of $\mathrm{IP}_{3}$ as a second messenger and DAG. Majority of the mGluRs of the group I increases excitation of cells by inhibition of the activity of potassium channels. Their inhibitory action resulting from the activation of small conductance (SK)-type Caactivated potassium channels was also described (Giessel and Sabatini, 2011). Group II of the mGluRs consists of $\mathrm{mGluR}_{2}$ and $\mathrm{mGluR}_{3}$. To group III belong 
following subclasses: $\mathrm{mGluR}_{4 \mathrm{~A}}, 4 \mathrm{~B}, \mathrm{mGluR}_{6}, \mathrm{mGluR}_{7 \mathrm{~A}}$, ${ }_{7 \mathrm{~B}}$ and $\mathrm{mGluR}_{8}$. All receptors of groups II and III inhibit activity of cAMP-ase in recombined expression systems and in brain, they modulate binding of protein $\mathrm{G}$, uncaging PIP2-dependent $\mathrm{K}^{+}$ channels (GIRKs) or voltage gated $\mathrm{Ca}^{2+}$ channels (VGCC) (Cartmell and Schoepp, 2000).

Expression of mGluRs of groups I and II was found in structures of CNS closely related with nociception: Spinal cord superficial fields, responsible for pain filling or modulation of neurotransmission in the peripheral receptors (all main groups of mGluRs). The highest expression of group I receptors $\left(\mathrm{mGluR}_{1,2,3}\right.$ and $\left.\mathrm{mGluR}_{5}\right)$ was revealed in neuronal plexuses of dorsal horns of the spinal cord, as well as in peripheral endings of these neurons (pre-synaptically) (Bhave et al., 2001; Carlton and Neugebauer, 2002; Walker et al., 2001; Zhang et al., 2004). Receptor proteins of $\mathrm{mGluR}_{4}$ and 7 were found in the presynaptic endings of sensory neurons of dorsal horns of the spinal cord (Azkue et al., 2000). In afferent endings of nociceptive nerves of dorsal horns, immunoreactivity against $\mathrm{mGluR}_{7}$ was estimated (Lee et al., 2007).

In different thalamus nuclei (with neural projection of spinal-thalamic tract from dorsal horns of spinal cord) the different mGluRs were also stained: $\mathrm{mGluR}_{1}$ - (Sillevis et al., 2000), $\mathrm{mGluR}_{2}$ and 3 - (Tamaru et al., 2001), mGluR $_{4}$ - (Bradley et al., 1999), mGluR 5 (Romano et al., 1995) and $\mathrm{mGluR}_{8}-$ (Duvoisin et al., 1995). Particularly strong expression of these receptors in that region was found for $\mathrm{mGluR}_{1}$ and 3 (Schoepp, 2001).

The important places for the projection of nociceptive receptors in dorsal horns of the spinal cord are reticular formation and Periaqueductal Gray (PAG). This is one of the most important centers for efferent analgesic signals in the spinal cord. The expression of $\mathrm{mGluR}_{5}$ in the PAG was confirmed (Azkue et al., 1997). Frontal lateralo-ventral region of medulla (RVM) is important for efferent analgesic processes. Also in other structures involved in transmission of pain information e.g., amygdala and association cortex, there are mGluRs, which are currently intensively studied.

It is known that peripheral receptors of group I $\left(\right.$ mGluR $_{1}$ and 5$)$ participate in the occurrence of nonevoked pain reminiscence and secondary hyperalgesia provoked mechanically by intraarticular or intradermal injection of carrageenin causing post-inflammatory pain (Lee et al., 2007). Peripheral application of the mGluR antagonists revealed antinociceptive effect. The specific role of spinal receptors (mGluRs) belonging to groups I and II in intermediating in nociception in behavioral studies was described in rats (Fundytus et al., 2001) and in sheep (Dolan and Nolan, 2000) as well as in electrophysiological studies in rats (Budai and Larsen, 1998). Intrathecal application of those antagonists in conscious sheep caused inhibition of allodynia provoked mechanically (Dolan and Nolan, 2002) and in rat model of neuropathic pain (Fisher et al., 1998). There are no detailed data on the role of central receptors of group I (mGluR) in acute intestinal pain, containing both vegetative and emotional, from higher cortex structures, components and not only spinal receptor or peripheral pain. Hence, the objective of the study is to find out the role of mGluRs antagonist infused intracerebroventricularly (i.c.v.) in an experimental model of intestinal colic (extension of descending colon wall) in conscious sheep. Acquainting a functional role of these receptors in central origin nociception may be helpful in an introduction of new analgesics into therapy of acute intestinal pain in animals.

\section{Materials and Methods}

\section{Preparation of Animals}

Experiment was performed on 6 mature Polish merino ewes weighing $35-45 \mathrm{~kg} \mathrm{B.W}$, being in anoestrus period. Food was withheld $24 \mathrm{~h}$ prior to the surgery. Analgesia was initiated by i.m. ketamine (Calypsovet, 20 mg.kg ${ }^{\square 1}$ B.W., GEDEON RICHTER, Budapest, Hungary) administration and 15 min. later $i . v$. infusion of pentobarbital anesthesia (Vetbutal, $20 \mathrm{mg} \cdot \mathrm{kg}^{-1}$ B.W., BIOWET, Pulawy, Poland) was performed. During unconsciousness, a permanent stainless steel cannula (31 $\mathrm{mm}$ in length and $0.5 / 2 \mathrm{~mm}$ in inner/outer diameter), was inserted into the lateral ventricle (on the left and/or the right side) of the brain, $10 \mathrm{~mm}$ above the bregma and five $\mathrm{mm}$ laterally from the midline suture using stereotaxic method described by Kania et al. (2001). When the animals recovered from general anesthesia, they were placed in individual boxes and maintained at an ambient temperature $\left(18-20^{\circ} \mathrm{C}\right)$, for 10 days to recover. Animals had free access to hay and water, except during the experimental period.

Experiment was carried out in four stages (each of six animals/sampling units). Every trial was performed simultaneously on two $12 \mathrm{~h}$ fasted animals, which were placed in two individual metabolic cages at one-week intervals. Experimental procedure lasted six months. Two days before the planned trial, a silicone cannula was inserted into the jugular external vein. It was done under local anesthesia by s.c. injection of $2 \mathrm{~mL}$ of $2 \%$ procaine (Polocaine hydrochloride, POLFA, Poland).

\section{Used Drugs}

In the present experiments the following drugs were used: L-2-Amino-3-Phosphonopropionic Acid (L-AP3) a nonselective metabotropic glutamate receptor (mGluR) blocker-(USP grade-A154, SIGMA-Aldrich), heparin (Heparinum-POLFA, Poland); reduced glutathione (Glutathione, Ethylester, SIGMA-RBI), procaine (2\% solution, Polocainum hydrochloricum-POLFA, Poland). L-AP3 was dissolved in $0.9 \% \mathrm{NaCl}$. 

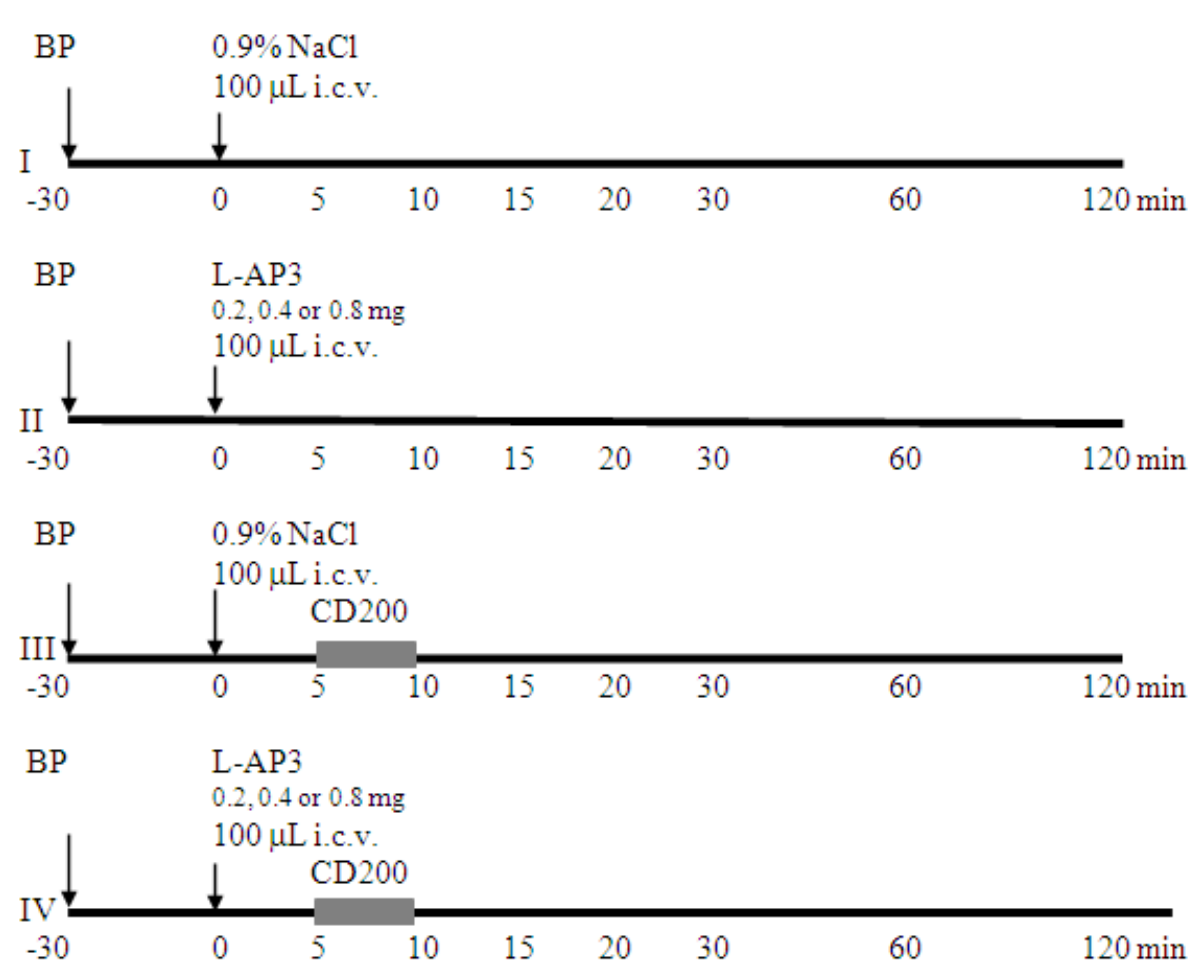

Fig. 1. Experimental timelines for the four test groups and blood sampling (I) $0.9 \%$ solution NaCl-100 $\mu$ L i.c.v. (II) L-AP3-0.2, 0.4 or $0.8 \mathrm{mg}$ in toto infused in $100 \mu \mathrm{L}$ of $0.9 \% \mathrm{NaCl}$ i.c.v (III) Descending Colon Distension (CD200) $-200 \mathrm{~mL}$ water (temp. $=$ $39^{\circ} \mathrm{C}$ ) placed into rubber balloon (IV) Descending Colon Distension (CD200) + L-AP3 premedication i.c.v. $(0.2,0.4$ or 0.8 $\mathrm{mg} /$ animal in toto. The time at which the balloon was inserted into colon is marked with „BP“

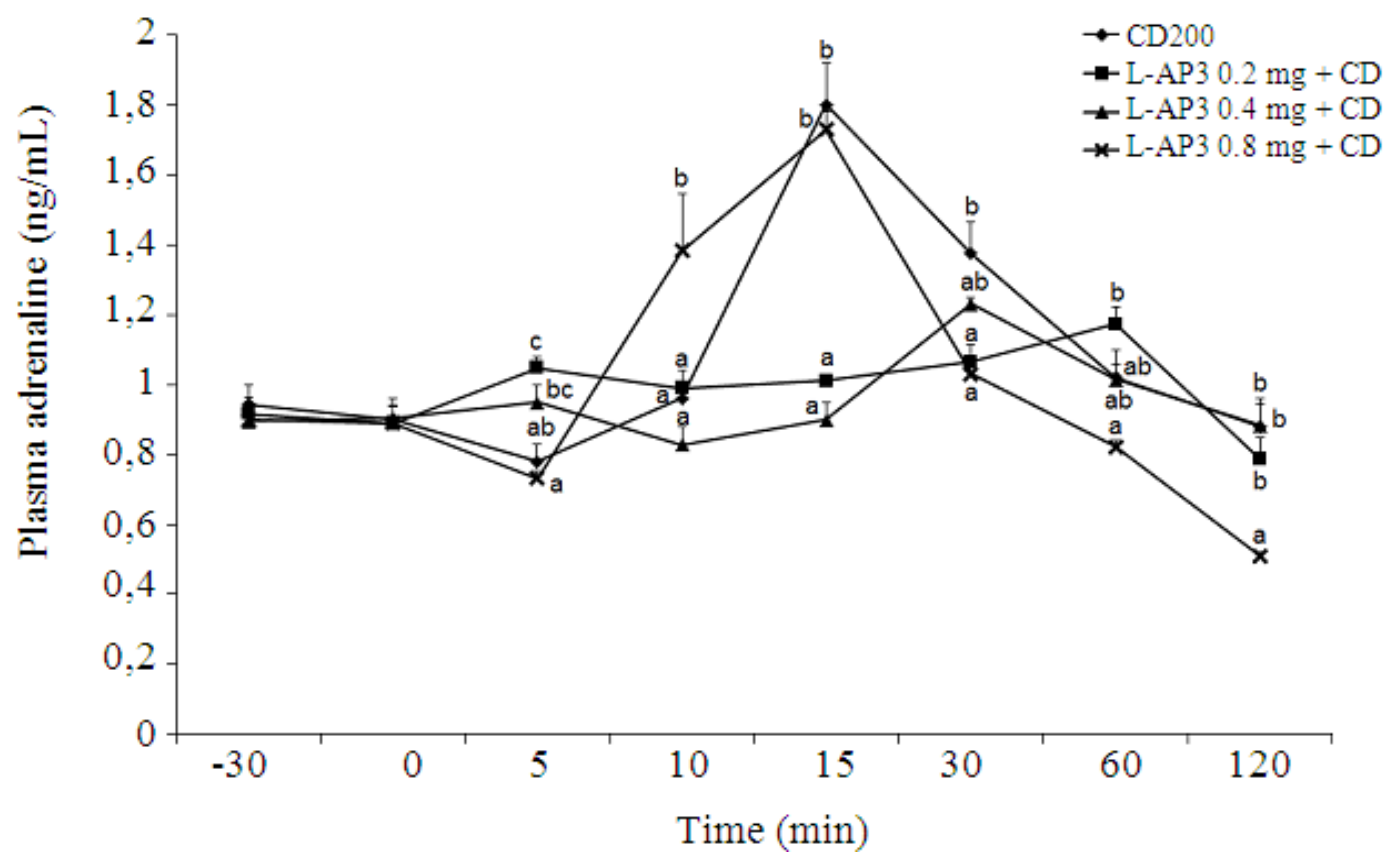

Fig. 2. Influence of the L-AP3 premedication $(0.2,0.4$ or $0.8 \mathrm{mg} / \mathrm{animal}$, i.c.v. infusions $5 \mathrm{~min}$ earlier) and the descending colon distension lasting 5 min (CD200) on plasma concentration of adrenaline in sheep $(x \pm S E M, n=6)$. — $-C D 200$; — ! - LAP3 $0.2 \mathrm{mg} /$ animal before CD200; — 4 L-AP3 $0.4 \mathrm{mg} /$ animal before CD200; — Г— L-AP3 $0.8 \mathrm{mg} /$ animal before CD200. $\mathrm{a}, \mathrm{b}, \mathrm{c}$-different letters indicate statistically significant difference between means measured in the same time $(\mathrm{p} \leq 0.05)$ 


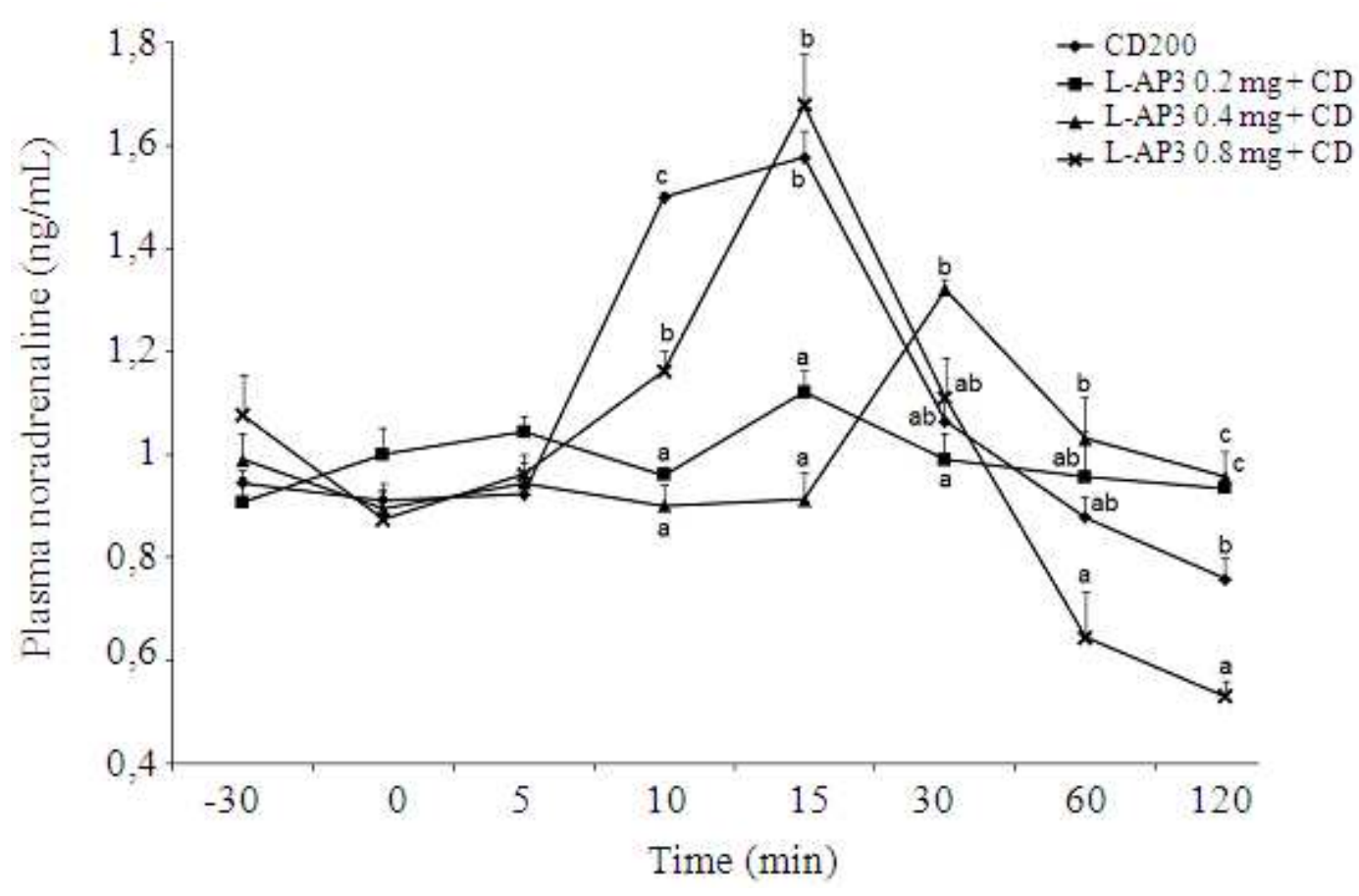

Fig. 3. Influence of the L-AP3 premedication $(0.2,0.4$ or $0.8 \mathrm{mg} /$ animal, i.c.v. infusions 5 min earlier) and the descending colon distension lasting 5 min $(\mathrm{CD} 200)$ on plasma concentration of noradrenaline in sheep $(\mathrm{x} \pm \mathrm{SEM}, \mathrm{n}=6)$. $\longrightarrow$ - CD200; —! L-AP3 $0.2 \mathrm{mg} / \mathrm{animal}$ before CD200; — - — L-AP3 $0.4 \mathrm{mg}$ /animal before CD200; — - — L-AP3 $0.8 \mathrm{mg} /$ animal before CD200. ${ }^{\text {a, b, c }}$-different letters indicate statistically significant difference between means measured in the same time ( $\left.\leq \leq 0.05\right)$

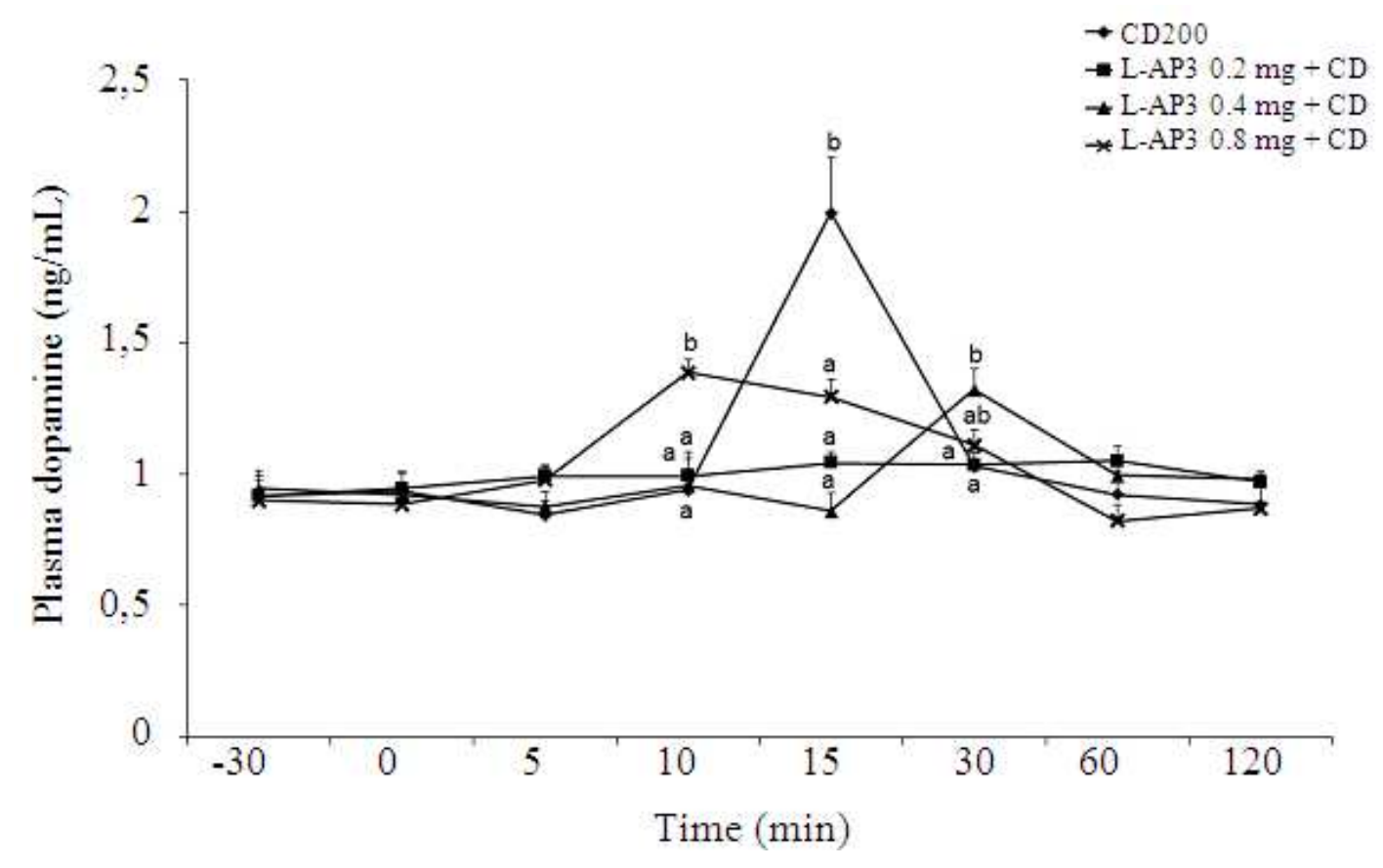

Fig. 4. Influence of the L-AP3 premedication $(0.2,0.4$ or $0.8 \mathrm{mg} / \mathrm{animal}$, i.c.v. infusions $5 \mathrm{~min}$ earlier) and the descending colon distension lasting 5 min (CD200) on plasma concentration of dopamine in sheep $(\mathrm{x} \pm \mathrm{SEM}, \mathrm{n}=6) . \longrightarrow-\mathrm{CD} 200$; - $\longrightarrow$ ! - LAP3 $0.2 \mathrm{mg}$ /animal before CD200; — - L L-AP3 $0.4 \mathrm{mg}$ /animal before CD200; — - — L-AP3 $0.8 \mathrm{mg} /$ animal before CD200, $\mathrm{a}, \mathrm{b}$ - different letters indicate statistically significant difference between means measured in the same time $(\mathrm{p} \leq 0.05)$ 
Table 1. The effect of the Descending Colon Distension (CD200) on behavioral and clinical symptoms (measured during 5 min) in sheep $(\mathrm{n}=6)$ not premedicated $(0.9 \% \mathrm{NaCl}$ i.c.v. $)$ and after the i.c.v. premedication with $0.4 \mathrm{mg} \mathrm{L}-\mathrm{AP} 3$ per animal in toto 5 min. before CD200

\begin{tabular}{|c|c|c|c|c|c|c|c|c|c|c|c|c|c|c|}
\hline \multirow{3}{*}{$\begin{array}{l}\text { Accompanying } \\
\text { symptoms }\end{array}$} & \multicolumn{14}{|c|}{ Minutes from descending colon distention $(200 \mathrm{~mL})$} \\
\hline & \multicolumn{2}{|l|}{$-5-0$} & \multicolumn{2}{|l|}{$0-5$} & \multicolumn{2}{|c|}{$5-10$} & \multicolumn{2}{|c|}{$10-15$} & \multicolumn{2}{|c|}{$25-30$} & \multicolumn{2}{|c|}{$55-60$} & \multirow{2}{*}{\multicolumn{2}{|c|}{$\begin{array}{l}115-120 \\
\text { CD AP3 +CD }\end{array}$}} \\
\hline & $\mathrm{CD}$ & $\mathrm{AP} 3+\mathrm{CD}$ & $\mathrm{CD}$ & $\mathrm{AP} 3+\mathrm{CD}$ & $\mathrm{CD}$ & $\mathrm{AP} 3+\mathrm{CD}$ & $\mathrm{CD}$ & $\mathrm{AP} 3+\mathrm{CD}$ & $\mathrm{CD}$ & $\mathrm{AP} 3+\mathrm{CD}$ & $\mathrm{CD}$ & $\mathrm{AP} 3+\mathrm{CD}$ & & \\
\hline Looking around ${ }^{*}$ & - & - & $3+$ & \pm & $3+$ & \pm & $2+$ & - & + & - & - & - & & - \\
\hline Defecation and/or urinating & - & - & + & - & + & - & + & \pm & - & + & - & - & - & - \\
\hline Head movements & - & - & $3+$ & - & $2+$ & \pm & - & - & - & + & - & - & - & - \\
\hline Stretching & - & - & + & - & + & & - & - & - & + & - & - & - & - \\
\hline Grinding & - & - & + & \pm & - & + & - & \pm & - & - & - & - & - & - \\
\hline Stretching out & - & - & $2+$ & - & + & - & - & \pm & - & - & - & - & & - \\
\hline Bleating & - & - & + & - & $2+$ & - & + & - & - & - & - & - & - & - \\
\hline Tachycardia & - & - & $2+$ & - & $2+$ & \pm & $2+$ & \pm & \pm & \pm & $3+$ & \pm & $3+$ & - \\
\hline Hyperventilation & - & - & - & - & + & \pm & + & \pm & + & - & + & - & + & - \\
\hline $\begin{array}{l}\text { Inhibition of } \\
\text { reticulo-rumen activity (\%) }\end{array}$ & - & - & 80 & 19 & 80 & 11 & 48 & 15 & 38 & 22 & 45 & - & 30 & - \\
\hline
\end{tabular}

*no reaction, \pm occasional, $2+$ quite frequently, 3+ frequently, 4+ very frequently

\section{Measure of the Heart and Ventilation Frequency}

Heart and respiratory rates were determined in all animals by examining the number of heartbeats as well as by observing the respiratory thoracic movements using stethoscope for one minute. Those measurements, as well as behavioral observations (5 min intervals), were carried out by the same person before each blood test for analysis.

\section{Determination of Catecholamines}

The hormones in blood plasma were measured in each animal $(\mathrm{n}=6)$. A rubber balloon $(10 \mathrm{~cm}$ in length) was introduced into the descending colon via the anus and left for $30 \mathrm{~min}$ in all animals (Fig. 1). At time 0 , via permanent cannula placed in the lateral ventricle of the brain (i.c.v.), the solution of $0.9 \% \mathrm{NaCl}(100 \mu \mathrm{L})$ or the solution of L-AP3 (in $0.9 \% \mathrm{NaCl}$ ) in the dose of $0.2,0.4$, or $0.8 \mathrm{mg} / 100 \mu \mathrm{L}$ were infused during one minute. The doses of L-AP3 corresponded to 5, 10 and $20 \mu \mathrm{g} \mathrm{kg}^{-1}$ B.W., respectively. After five minutes from the i.c.v. infusion (time 0), the balloon was filled with $200 \mathrm{~mL}$ of warm water (CD200) and the distension of the descending colon was maintained for five minutes. Blood was collected $30 \mathrm{~min}$ prior the experiment, just before the placement of the rubber balloon into descending colon and then at 0 (before i.c.v. infusions), 5 (before CD200), 10 (CD200), 15, 30, 60 and $120 \mathrm{~min}$ after i.c.v. infusions (Fig. 1).

Blood samples were taken from the jugular external vein and collected into $10 \mathrm{~mL}$ test tubes containing reduced glutathione $(0.05 \mathrm{mM})$. The plastic tubes were maintained on ice and after centrifugation, plasma was stored in $-80^{\circ} \mathrm{C}$ until beginning of the analytical process.

The determination of Catecholamines (CA) was performed by the HPLC method with electrochemical detector (Wang et al., 1999).

\section{Statistical Analysis}

Statistical analysis of the results was performed using one-way analysis of variance. The statistical relevance of the results was determined with the post-hoc TukeyKramer test. The comparison between the two groups was performed using the $t$-test. The results are presented as $\mathrm{x} \pm \mathrm{SEM}$. A $\mathrm{p}$ value less or equal to 0.05 was considered statistically significant in all tests.

\section{Ethical Considerations}

The experiment was performed with the accordance to the Principles of Laboratory Animal Care (NIH publication no. 86-23, revised 1985) as well as the specific national laws on protection of animal (National regulation for the animal protection-1997, Dz. U. 23 XI; Permission of 3rd Local Ethical Commission: No 9/2001 issued 11.01.2001).

After completion of the experiments, all animals were subjected to euthanasia using Morbital (BIOWET, Poland).

\section{Results}

The effect of the colon descending distension (CD200) upon behavioral symptoms, clinical signs and plasma catecholamine concentrations was studied. Prior to any manual activity no deviation from normal behavior was observed in a pairs of animals, which were simultaneously placed in separate cages. The average cardiac frequency was 65.5 and the rate of respiration 18.6. $\mathrm{min}^{\square 1}$. After the insertion of an empty rubber balloon into the colon 30 min prior to the CD200, no significant changes were observed in animal behavior or in cardiac action $\left(67.5\right.$ beats. $\left.\min ^{\square 1}\right)$, respiration frequency $\left(17.2 \cdot \mathrm{min}^{\square 1}\right.$ ). There were no significant differences amongst results noticed prior to the insertion of the balloon inside the descending colon. 
Infusion of the $100 \mu \mathrm{L} 0.9 \% \mathrm{NaCl}$ i.c.v. during one minute, $5 \mathrm{~min}$ before the distension of the descending colon did not cause any significant changes in behavioral responses (Table 1), clinical symptoms. Concentration of adrenaline (from $0.84 \pm 0.06$ to $0.88 \pm 0.04$ ng.mL ${ }^{\square}$; Fig. 2), noradrenaline (from $0.91 \pm 0.02$ to $0.92 \pm 0.01 \mathrm{ng} \cdot \mathrm{mL}^{-1}$; Fig. 3) as well as dopamine (from $0.74 \pm 0.07$ to $0.85 \pm 0.09$ ng.mL ${ }^{\square 1}$; Fig. 4) in blood plasma were not significantly affected during $5 \mathrm{~min}$ after $\mathrm{NaCl}$ i.c.v. infusion. That was in accordance with previous studies (Kania and Sutiak, 2011).

\section{The Influence of the Distension of the Colon Descending (CD200)}

The CD200 treatment caused highly significant changes in the behavior, clinical symptoms (Table 1), as well as in CA concentrations of animals (Fig. 2-4). The following changes of animal behavior linked with the action of algesic (nocifensive) factor were observed: An increase in general motricity, bleating, teeth clenching, prostration, wetting, defecation, tachycardia (from 60.3 to 76.2 beats. $\min ^{\square 1}$ ) and hyperventilation (from 16.8 to $24.3 \mathrm{~min}^{\square}$ ) (Table 1).

The descending colonal distension caused a significant increase in plasma catecholamine concentrations. Adrenaline (Fig. 2) reached the peak level five minutes after CD200 termination (1.79 \pm 0.09 ng. $\left.\mathrm{mL}^{\square 1}\right)$. The value before the CD200 was $0.78 \pm 0.05$ ng. $\mathrm{mL}^{\square 1}$ and it increased by $76.2 \%$ (the average of values measured at 5 and $20 \mathrm{~min}$. following the CD200 termination). Noradrenaline concentration in plasma (Fig. 3) increased significantly already during the CD200, earlier than adrenaline level did. Five minutes after termination of the CD200, the noradrenaline concentration was higher by $62 \%$ (from $0.92 \pm 0.01$ before to $1.57 \pm 0.05 \mathrm{ng} \cdot \mathrm{mL}^{\square 1}$ ). This increase was followed by a significant decrease to $0.76 \pm 0.04 \mathrm{ng} \cdot \mathrm{mL}^{\square 1}$ at 110 min after the termination of the CD200 (Fig. 3). This increase was statistically significant up to $15 \mathrm{~min}$ of the experiment $(p \leq 0.05)$. The concentration of dopamine (Fig. 4) increased significantly from $0.85 \pm 0.09$ before $\mathrm{CD} 200$ to $2.00 \pm 0.21 \mathrm{ng} . \mathrm{mL}^{\square 1}$ at $15 \mathrm{~min}$ (five minutes after termination of the CD200).

\section{The Influence of the L-AP3 during the CD200}

One-minute L-AP3 i.c.v. infusion ( $0.4 \mathrm{mg}$ in toto) did not have any significant impact on behavior and clinical symptoms (Table 1).

The i.c.v. infusion of $0.4 \mathrm{mg}$ L-AP3 in toto given five minutes prior to the CD200 decreased intensity or even prevented appearance of clinical signs of visceral pain caused by the CD200 test (Table 1). In sheep without the premedication, an intensive tachycardia was noticed (average from 65 to 78 heart bits.min ${ }^{\square}$ ) and in the group of animals receiving L-AP3 the pain caused by the CD200 decreased significantly; the heart rate average from 65 to 54 bits.min ${ }^{\square}$. Respiration frequency was reduced from 25 to $15 . \mathrm{min}^{\square}$, respectively (Table 1 ).

The i.c.v. infusions of 0.2 or $0.4 \mathrm{mg} \mathrm{L}-\mathrm{AP} 3$ in toto given five minutes prior to the CD200 decreased adrenaline concentration caused by visceral pain provoked by the CD200 (Fig. 2). However in animals treated with the highest dose of the L-AP3 $(0.8 \mathrm{mg}$ in toto), a significant increase of plasma adrenaline from $0.90 \pm 0.11$ to $1.45 \pm 0.44$ ng. $\mathrm{mL}^{\square 1}(+61.1 \%)$ during the $\mathrm{CD} 200$ and to $1.68 \pm 0.12$ ng.mL ${ }^{\square 1}(+86.6 \%)$ ten minutes later was noticed. The significant inhibition of noradrenaline concentration in plasma during and after the CD200 by lower doses of the L-AP3 (0.2 and $0.4 \mathrm{mg}$ in toto) was observed (Fig. 3). The i.c.v. infusion of 0.8 $\mathrm{mg}$ L-AP3 in toto did not inhibit a rise of plasma noradrenaline caused by the CD200. Five minutes after termination of the CD200 (15 min after infusion), the plasma NA level was $1.68 \pm 0.1$ ng.mL ${ }^{\square 1}$, numerically higher than in sheep infused with $0.9 \% \mathrm{NaCl}$. Moreover, both adrenaline and noradrenaline concentrations in plasma were significantly lower at $120 \mathrm{~min}$ after the i.c.v. infusion of $0.8 \mathrm{mg} \mathrm{L}-\mathrm{AP} 3$ in toto $(0.51 \pm 0.01$ and $0.53 \pm 0.03$ ng. $\mathrm{mL}^{\square}$, respectively).

All doses of L-AP3 prevent an increase of plasma dopamine level five minutes after the termination of the CD200 (15 min after infusion). However, the highest dose of the L-AP3 (0.8 $\mathrm{mg}$ in toto $)$ in combination with the CD200 increased significantly plasma DA level $\left(1.39 \pm 0.05 \mathrm{ng} . \mathrm{mL}^{\square 1}\right)$ as compared to the other treatments (Fig. 4).

\section{Discussion}

The L-AP3 prevents normal homeostatic process by blocking presynaptic glutamate receptors mGluRs. During the high activity periods, the high EPSPs were observed in neuromuscular plates. Centrally applied LAP3 in physiological solutions provoked the situation in which brain neurons might not differentiate the glutamate concentration in the synaptic gap, what occurs in the case of the neuromuscular plate (Ames et al., 2002).

The L-AP3 binding auto-receptors, cancels a glutamate release efficiently breaking the transduction of the action potential. It was confirmed by the amplitudes of the EPSPs obtained in the conditions of: A low frequency excitation $(0.5 \mathrm{~Hz})$, a high concentration of glutamate and the DL-AP3 addition to a water bath with neuromuscular plate. The results of Ames et al. (2002) confirmed current knowledge about the character of group II glutamate receptors. It was shown, that group II Metabotropic Glutamate Receptors (mGluRs) play key role in modulation of the glutamate concentration (Schoepp, 2001). Low glutamate concentration in 
synapse does not excite group II metabotropic glutamate receptors to the inhibition of glutamate releasing. During the high activity of the neuromuscular plate $(10 \mathrm{~Hz}$ excitation), the neuron decreases the flow rate of glutamate to the synaptic gap. This fact confirms the existence of negative feedback.

It may be supposed in our work, that the preventive action of the L-AP3 infused into the cerebral ventricle in the doses of 0.2 and $0.4 \mathrm{mg}$ in toto in sheep subjected CD200 test, was related to the breaking of the noxious signaling in the CNS (so called pain gating). It was followed by the lack of the negative reactions accompanying visceral pain, caused mechanically by the 5 min distension of the descending colon wall with the balloon filled with $200 \mathrm{~mL}$ of water. The CD200 increased activity of sympatho-medullo-adrenal system (higher plasma concentration of catecholamines) and of motivatio-emotional system causing many behavioral changes. The following clinical symptoms of this stimulation were observed: Tachycardia, hyperventilation, defecation and/or urination, looking to the sides, escaping reflex from the experimental cage and other behavioral syndromes (Table 1). On the base of the biochemical and behavioral analyses, mechanical pain stimulus appeared to be stressogenic and caused general physical stress in experimental animals (Kania et al., 2001).

Considering an action of L-AP3, as a potential antagonist of the CNS group I metabotropic receptors and its antynociceptive action, the analysis of the CD200 effect after $10 \mathrm{~min}$ from the premedication was performed. The L-isomeric form of the AP3 was applied into lateral cerebral ventricle (i.c.v.) at the doses of 0.2 , 0.4 and $0.8 \mathrm{mg} /$ animal during one minute (see material and methods). The premedication with this antagonist of the group I Metabotropic Glutamate Receptors (mGluRs) cancelled, prevented or inhibited the influence of noxious factor (CD200). The L- diffracted AP3 isomer, infused i.c.v. in the doses of 0.2 and $0.4 \mathrm{mg}$ in toto at five minutes before the colon distension with water (200 $\mathrm{mL}$ ) during five minutes, significantly decreased the release of cortisol and catecholamines (stress hormones), diminished or weakened emotional reactions of animals related to the excitation of intracerebral motivational structures i.e., limbic system, striatum, globus pallidus, thalamus, hypothalamus and medial forebrain bundle (Kania and Siwecka, 2003).

Peripheral damaging stimuli excite specific receptors on nociceptive afferent neurons, evoking the action potentials and releasing of glutamate and neuromodulatory peptides from axon endings in spinal cord. Afferent neuron endings form terminal synaptic bulbs with neurons of dorsal horns of spinal cord and these cells project to the perception cortex centers. Glutamate released from the endings of afferent neurons affect neurons of dorsal horns by excitation of two groups of receptors: Glutamate ionotropic receptors
(iGluRs) and glutamate metabotropic receptors (mGluRs). The iGluRs are ligand-gated ion channels: NMDA, AMPA and kainic receptors. These receptors participate in quick synaptic transmission from afferent neurons to dorsal spinal horn and to superior sensory centers in brain. Receptors mGluRs include whole family of the receptors related through proteins $G$ to different intracellular systems of the secondary messengers. These receptors mediate in neuromodulating action of glutamate (Varney and Gerey, 2002). Glutamate receptors are present in both, peripheral and central nervous systems. Fisher et al. (1998) found the localizations of mGluRs in spinal cord and brain. Bhave et al. (2001), Carlton and Neugebauer (2002), Walker et al. (2001) stated that the mGluRs localized already in the first ascending neurons may participate in the modulation of pain. Kirchgessner (2001) in studies with Guinea pigs and rats revealed the presence of glutamate receptors of both types, ionotropic and metabotropic (particularly of group I mGluRs), in ganglions of mesenteric plexuses and intestinal epithelium. The author claimed that these receptors play an important role in regulation of intestinal peristaltics and in gastrointestinal secretion. Hence, the application of the antagonists of metabotropic and/or ionotropic receptors as potential analgesic drugs may work in peripheral as well as in central nervous system.

\section{Conclusion}

The results of analgesic action of the L-AP3, in mechanically evoked pain test (descending colon distension), which occurred as the antagonist of the group I mGluR receptors, confirm literature data obtained after application of specific and non-specific antagonists of mGluR, including group I, in chronic and acute pain tests in rodents. There is no doubt, that plasticity of synapses mediating in nociceptive process needs the activation of the NMDA receptors. However, in many cases this plasticity needs also modulation by mGluR (Neugebauer, 2002). As it was emphasized in the introduction, many subtypes of mGluRs are present in noxious tracts and studies performed in recent years determined the role of the mGluRs in noxious transduction and synaptic plasticity. The application of the mGluR ligands into brain ventricle in sheep, caused that these molecules bind firmly to the specific group I mGluRs preventing in this way neurons from depolarization induced by specific ligand i.e., glutamate. Glutamate, as a specific agonist of the mGluRs increases ability and rate of transduction of noxious stimuli and intensifies sensitivity of the pain perception centers including spinal cord, thalamus and brain prefrontal cortex. The prior i.c.v. premedication with drug of the opposite action-antagonistic to glutamate-resulted in its firm binding to the group I mGluRs. Even massive release of glutamate resulting from CD200 did not overcome the 
blockade of stimulus transmission to the central structures of pain transduction. Moreover, this blockade did not allow, at least periodically, eliciting the analyzed cascade of biochemical and behavioral changes that might be a consequence/symptoms of noxious stimulus.

The L-AP3 reversed the sensitivity and prevented the development of the central perceptivity caused by the joint inflammation (Neugebauer et al., 1994). In our study, we extrapolated doses applied peripherally in rodents, considering the amount of active substances in organic fluid. Such calculated doses of the L-AP3 were 10 -fold reduced (i.m. injection versus i.c.v. injection), resulting in 5,10 and $20 \mu \mathrm{g} \cdot \mathrm{kg}^{-1}$ B.W., what in turn corresponds to $0.2,0.4$ and $0.8 \mathrm{mg}$ per $40 \mathrm{~kg}$ animal, respectively. Lower doses ( 0.2 and $0.4 \mathrm{mg}$ in toto) of the tested substance (L-AP3) were not too big for sheep, because later no adverse effects were observed. We observed in this study that the highest dose $(0.8 \mathrm{mg} \mathrm{L}$ AP3 in toto; $20 \mu \mathrm{g} \bullet \mathrm{kg}^{-1}$ B.W.) initially (10-15 min. after i.c.v. infusion) increased and finally significantly decreased both adrenaline and noradrenaline levels in plasma (120 min after i.c.v. infusion and $110 \mathrm{~min}$ after the termination of the distention of the descending colon). Knowing the role of catecholamines in the organism, the physiological significance of these findings is difficult to discuss, but such changes in catecholamine concentrations may affect whole metabolism of the body. Hewitt (2000) recognized significant adverse effects after the chronic application of non-specific antagonists of particular subgroups of the NMDA receptors, what in turn caused the critical opinions on the role of the NMDA receptors in the normal excitatory synaptic transduction in nervous system. Those adverse effects included fatigue, dizziness, psychoses, hyperactivity and in the case of the high doses of the NMDA antagonists: Memory losses and damage of neurons (Eide et al., 1995).

It is interesting that stimulation of the mGluRs increases activity of the NMDA receptors in dorsal horns and probably this higher activity modulates synaptic plasticity dependent on the NMDA receptors in this localization. Drugs that potentially might specifically bind to the mGluRs, which are responsible for long-time changes in nociception, can have negligible effect on excitatory transduction in normal conditions. However, they can efficiently change abnormally increased transduction, what occurs in chronic pain stage. Hence, the antagonists of mGluRs may well serve in the intervention treatments during trauma or as analgesics in chronic pain, without obvious adverse effects inseparably related to the application of the antagonists of the NMDA receptors.

\section{Author's Contributions}

All authors equally contributed in this work.

\section{Ethics}

This article is original and contains unpublished material. The corresponding author confirms that all of the other authors have read and approved the manuscript and no ethical issues involved.

\section{References}

Ames, P., N. Heto and R. Ramdial, 2002. L-2-Amino-3phosphonopropionic acid modulates the release of glutamate by blocking presynaptic group II mGlu receptors at neuromuscular junction in Procambarus clarkii. Pioneering Neurosci., 3: 21-26.

Azkue, J.J., J.M. Mateos, I. Elezgari, R. Benitez and Alexandra Osorio et al., 2000. The metabotropic glutamate receptor subtype mGluR $2 / 3$ is located at extrasynaptic loci in rat spinal dorsal horn synapses. Neurosci. Letteers, 287: 236-238. DOI: 10.1016/S0304-3940(00)01189-7

Azkue, J.J., T. Knopfel, R. Kuhn, J.M. Mateos and P. Grandes et al., 1997. Distribution of the metabotropic glutamate receptor subtype mGluR5 in rat midbrain periaqueductal gray and relationship with spinofugal afferents. Neuroscience Letters, 228: 1-4. DOI: 10.1016/S0304-3940(97)00357-1

Bhave, G., F. Karim, S.M. Carlton and R.W. Gereau, 2001. Peripheral group I metabotropic glutamate receptors modulate nociception in mice. Nature Neurosci., 4: 417-423. DOI: 10.1038/86075

Bradley, S.R., D.G. Standaert, K.J. Rhodes, K.J. Rhodes and H.D. Rees et al., 1999. Immunohistochemical localization of subtype $4 \mathrm{a}$ metabotropic glutamate receptors in the rat and mouse basal ganglia. J. Comparative Neurology, 407: 33-46.

DOI:

$10.1002 /($ SICI)10969861(19990428)407:1<33::AID-CNE3>3.0.CO;2-G

Budai, D. and A.A. Larson, 1998. The involvement of metabotropic glutamate receptors in sensory transmission in dorsal horn of the rat spinal cord. Neuroscience, 83: 571-580. DOI: $10.1016 / \mathrm{S} 0306-4522(97) 00390-4$

Carlton, S.M. and V. Neugebauer, 2002. Peripheral metabotropic glutamate receptors as drug target for pain relief. Expert Opinion Therapeuutic Targets, 6: 349-361. DOI: 10.1517/14728222.6.3.349

Cartmell, J. and D.D. Schoepp, 2000. Regulation of neurotransmitter release by metabotropic glutamate receptors. J. Neurochem., 75: 889-907.

Dolan, S. and A.M. Nolan, 2000. Behavioral evidence supporting a differential role for spinal group I and II metabotropic glutamate receptors in spinal nociceptive transmission. Neuropharmacology, 39: 1132-1138. DOI: 10.1016/S0028-3908(99)00200-2 
Dolan, S. and A.M. Nolan, 2002. Behavioral evidence supporting a differential role for spinal group I and II metabotropic glutamate receptors in inflammatory hyperalgesia in sheep. Neuropharmacology, 43: 319-326. DOI: 10.1016/S0028-3908(02)00107-7

Duvoisin, R.M., C. Zhang and K. Ramonell, 1995. A novel metabotropic glutamate receptor expressed in the retina and olfactory bulb. J. Neurosci., 15: 3075-3083.

Eide, P.K., A. Stubhaug, I. Oye and H. Breivik, 1995. Continuous subcutaneous administration of the NMethyl-d-Aspartic Acid (NMDA) receptor antagonist ketamine in the treatment of post-herpetic neuralgia. Pain, 61: 221-228.

DOI: 10.1016/0304-3959(94)00182-E

Fisher, K., M.E. Fundytus, C.M. Cahil and T.J. Coderre, 1998. Intrathecal administration of the mGluR compound, (S)-4CPG, attenuates hyperalgesia and allodynia associated with sciatic nerve constriction injury in rats. Pain, 77: 59-66.

DOI: 10.1016/S0304-3959(98)00082-7

Fundytus, M.E., K. Yashpal, J.G. Chabot, M.G. Osborne and C.D. Lefebvre et al., 2001. Knockdown of spinal metabotropic glutamate receptor 1 (mGluR1) alleviates pain and restores opioid efficacy after nerve injury in rats. Brit. J. Pharmacol., 132: 354-367. DOI: $10.1038 /$ sj.bjp.0703810

Giessel, A.J. and B.L. Sabatini, 2011. Boosting of synaptic potentials and spine ca transients by the peptide toxin SNX-482 requires alpha-1E-encoded voltage-gated ca channel. PLoS One, 6: e20939. DOI: 10.1371/journal.pone.0020939

Hewitt, D.J., 2000. The use of NMDA-receptor antagonists in the treatment of chronic pain. Clin. J. Pain, 16: S73-S79.

Kania, B.F. and B. Siwecka, 2003. Pharmacological and therapeutical aspects of pain attenuation in animals. Magazyn Weterynaryjny, 12: 63-66.

Kania, B.F. and V. Sutiak, 2011. Influence of centrally administered diltiazem on behavioural responses, clinical symptoms, reticulo-ruminal contractions and plasma catecholamine level after experimentally induced duodenal distension in sheep. Res. Vet. Sci., 90: 291-297.

Kania, B.F., D. Wronska and K. Romanowicz, 2001. Autonomic system and hypothalamo-hypophysocortico-surrenalienne reactions in sheep during duodenal distension. Medycyna Weterynaryjna, 57: 338-341.

Kirchgessner, A.L., 2001. Glutamate in the enteric nervous system. Currnt Opinion Pharmacol., 1: 591-596. DOI: 10.1016/S1471-4892(01)00101-1

Lee, K.S., J. Kim, Y.W. Yoon, Lee Min-Goo and Seung Kil Hong et al., 2007. The peripheral role of group I metabotropic glutamate receptors on nociceptive behaviors in rats with knee joint inflammation. Neurosci. Lett., 416: 123-127.

DOI: 10.1016/j.neulet.2007.01.063
Neugebauer V., T. Lücke and H.G. Schaible, 1994. Requirement of metabotropic glutamate receptors for the generation of inflammation-evoked hyperexcitability in rat spinal cord neurons. Eur. J. Pharmacol., 6: 1179-1186. PMID: 7524965

Neugebauer, V., 2002. Metabotropic glutamate receptors-important modulators of nociception and pain behavior. Pain, 98: 1-8.

DOI: 10.1016/S0304-3959(02)00140-9

Pin, J.P. and R. Duvoisin, 1995. The metabotropic glutamate receptors: Structure and functions. Neurpharmacology, 34: 1-26.

DOI: 10.1016/0028-3908(94)00129-G

Romano, C., M.A. Sesma, C.T. Mc Donald, K. O'malley and A.N. Van Den Pol et al., 1995. Distribution of metabotropic glutamate receptor mGluR5 immunoreactivity in rat brain. J. Comparative Neurology, 355: 455-469.

DOI: $10.1002 /$ cne. 903550310

Schoepp, D.D., 2001. Unveiling the functions of presynaptic metabotropic glutamate receptors in the central nervous system. J. Pharmacol. Experim. Therapeutics, 299: 12-20.

Sillevis, S.P., A. Kinoshita, B. De Leeuw, Wiebe Moll and Michiel Coesmans et al., 2000. Paraneoplastic cerebellar ataxia due to autoantibodies against a glutamate receptor. New England J. Med., 342: 21-27. DOI: 10.1056/NEJM200001063420104

Tamaru, Y., S. Namura, N. Mizuno and Shigemoto, 2001. Distribution of metabotropic glutamate receptor mGluR3 in the mouse CNS: Differential localization relative to pre- and postsynaptic sites. Neuroscience, 106: 481-503. DOI: 10.1016/S0306-4522(01)00305-0

Varney, M.A. and I.V. Gereau, 2002. Metabotropic glutamate receptor involvement in models of acute and persistent pain: Prospects for the development of novel analgesics. Current Drug Targets-CNS Neurol Disorders, 1: 283-296.

Walker, K., M. Bowes, M. Panesar, A. Davis and C. Gentry et al., 2001. Metabotropic glutamate receptor subtype 5 (mGlu5) and nociceptive function: I. Selective blockade of mGlu5 receptors in models of acute, persistent and chronic pain. Neuropharmacology, 40: 1-9. DOI: 10.1016/S0028-3908(00)00113-1

Wang, Y., D.S. Fice and P.K.F. Yeung, 1999. A simple high-performance liquid chromatography assay for simultaneous determination of plasma norepinephrine, epinephrine, dopamine and 3,4dihroxyphenyl acetic acid. J. Pharmacol. Biomed. Analyses, 21: 519-525.

DOI: 10.1016/S0731-7085(99)00117-X

Zhang, G.H., S.S. Min, S.K. Lee, Back and S. Keun et al., 2004. Intraarticular pretreatment with ketamine and memantine could prevent arthritic pain: Relevance to the decrease of spinal c-Fos expression in rats. Anesthesia Analgesia, 99: 152-158.

DOI: 10.1213/01.ANE.0000117141.76392.65 